\title{
Imported malaria in a non-endemic area: the experience of the university of Campinas hospital in the Brazilian Southeast
}

\author{
João C K Dos-Santos ${ }^{1,2}$, Rodrigo N Angerami ${ }^{3}$, Catarina M S Castiñeiras ${ }^{1}$, Stefanie C P Lopes ${ }^{1}$, Letusa Albrecht ${ }^{1}$, \\ Márcia T Garcia ${ }^{3}$, Carlos E Levy ${ }^{5}$, Maria L Moretti ${ }^{3,4}$, Marcus V G Lacerda ${ }^{6,7}$ and Fabio T M Costa ${ }^{1 *}$
}

\begin{abstract}
Background: Although malaria in Brazil almost exclusively occurs within the boundaries of the Amazon Region, some concerns are raised regarding imported malaria to non-endemic areas of the country, notably increased incidence of complications due to delayed diagnoses. However, although imported malaria in Brazil represents a major health problem, only a few studies have addressed this subject.

Methods: A retrospective case series is presented in which 263 medical charts were analysed to investigate the clinical and epidemiological characterization of malaria cases that were diagnosed and treated at Hospital \& Clinics, State University of Campinas between 1998 and 2011.

Results: Amongst all medical charts analysed, 224 patients had a parasitological confirmed diagnosis of malaria. Plasmodium vivax and Plasmodium falciparum were responsible for $67 \%$ and $30 \%$ of the infections, respectively. The majority of patients were male (83\%) of a productive age (median, 37 years old). Importantly, severe complications did not differ significantly between P. vivax (14 cases, 9\%) and P. falciparum (7 cases, 10\%) infections.

Conclusions: Severe malaria cases were frequent among imported cases in Brazil outside of the Amazon area. The findings reinforce the idea that $P$. vivax infections in Brazil are not benign, regardless the endemicity of the area studied. Moreover, as the hospital is located in a privileged site, it could be used for future studies of malaria relapses and primaquine resistance mechanisms. Finally, based on the volume of cases treated and the secondary complications, referral malaria services are needed in the non-endemic areas of Brazil for a rapid and efficient and treatment.
\end{abstract}

Keywords: Malaria, Non-endemic area, Brazil, Plasmodium vivax, Plasmodium falciparum, Severity, Epidemiology

\section{Background}

Despite intense global efforts to control malaria, nonimmune and semi-immune travellers living in nonendemic areas remain a highly vulnerable group for malaria infection, especially due to delayed diagnosis and increased risks of complications. Therefore, although the clinical outlook for malaria in previously healthy adults living in endemic areas tends to be mild, the absence of immunity and delayed or misdiagnosis (up to 40\% [1]) may predispose infected persons to more severe presentations in

\footnotetext{
* Correspondence: fabiotmc72@gmail.com

'Departamento de Genética, Evolução e Bioagentes, Instituo de Biologia, Universidade Estadual de Campinas (UNICAMP), Campinas, SP, Brazil Full list of author information is available at the end of the article
}

imported cases of disease. Indeed, the chances of death are 80 to 100 times higher for malaria cases diagnosed outside of endemic areas [1-3].

Approximately $60 \%$ of malaria cases in the Americas occur in Brazil [4], and these almost exclusively occur in the Amazon Region. Today, most cases are diagnosed and treated at the same place where infection was acquired within 48 hours of the onset of symptoms, according to the Brazilian Ministry of Health. However, some regions of the country outside of the Amazon Region still receive patients presenting with malaria, either from the Amazon Region or from other countries, mainly Latin American and African nations. Although malaria is a major health problem in Brazil, with 177,783 cases registered in 
the Amazon Region in 2013 (more than 99\% of Brazilian cases occur in the Amazon Region), few studies have analysed the epidemiology and major complications triggered by this infection outside of endemic areas.

The Hospital \& Clinics of the State University of Campinas (HC-UNICAMP) is one of the fourteenreferral centers for the diagnosis and treatment of malaria in the Brazilian State of São Paulo. The region was formerly endemic for malaria, with a great number of autochthonous cases in the early decades of the 20th century [5]. In the 1960s, the Malaria Eradication Campaign led to a sharp drop in the number of autochthonous cases and, from 1980 to 2000, only one autochthonous case was reported in the Campinas region (6) [6]. Here, a retrospective case series is presented that analyses 263 medical charts for the clinical and epidemiological characteristics of malaria cases treated at HC-UNICAMP from January 1998 to April 2011.

\section{Methods}

\section{Ethical approval}

The informed consent waiver was approved by the Research Ethics Committee of the University of Campinas (number 1283/2011).

\section{Study design and subject enrollment}

The study was designed as a retrospective case series and took place at the HC-UNICAMP. Hospital \& Clinics, State University of Campinas (S $22^{\circ} 49^{\prime}$, W $47^{\circ} 03^{\prime}$, Campinas, Brazil) is a tertiary hospital with 409 beds; 471,338 medical consultations and emergency treatments were performed in 2012. The hospital has a coverage area of more than 100 municipalities in the areas surrounding Campinas, which includes a population of 5,000,000 in these municipalities [7].

Patients seen at HC-UNICAMP who received a confirmed diagnosis of malaria that was reported by its Hospital Epidemiology Division (NVE-UNICAMP) were selected. Diagnoses had been confirmed based on analysis of thick and thin blood films (TBF) that were examined by trained experienced staff. Patients were enrolled in this study, regardless of the species of Plasmodium infection identified, from January 1998 to April 2011. PCR was not routinely performed to confirm the Plasmodium species that caused an infection; however a senior microscopist systematically performed quality control. Only patients with accessible medical charts were enrolled. A standard questionnaire was used to register data obtained from the medical charts, such as demographic profile, time of clinical disease, referred previous malarial infections, travel history, peripheral blood parasitaemia, clinical and laboratory profiles, physical examination and the prescribed anti-malarial regimen.
Malaria patients at HC-UNICAMP are treated following the Brazilian guidelines for the treatment of malaria (Brazilian Ministry of Health, 2010) [8]. Patients were categorized as severe or non-severe according to 2010 World Health Organization (WHO) criteria [9]. WHO does not have a guideline to define malaria severity in infections by $P$. vivax. Since its absence, Lacerda et al. [10] argued that the WHO criteria used for P. falciparum infection fits malaria severity found in $P$. vivax infection. Therefore, the same criteria for both species were used. Because some patients were treated for malaria at the HC-UNICAMP for two or more episodes of malaria, only the first confirmed case registered on the medical chart was considered in the analysis. Patients were divided into residents $(n=56)$ and travellers $(n=87)$ based on the time that they stayed in the endemic area; a stay of more than 12 months was characterized as residence. Differences for which $P<0.05$ were considered to be statistically significant.

\section{Relapses}

After treatment, TBF were performed to verify cure. Blood films were checked at days 15, 45, 75 and 105 after treatment for patients with $P$. vivax malaria. Relapses were defined as the cases in which, after treatment and a negative TBF, subjects presented a new TBF with a positive result more than 28 days after starting anti-malarial treatment. Moreover, a case was only considered to be a relapse if the patient did not return to an endemic area during the follow-up period.

\section{Drug regimens}

Drug regimens followed Brazilian guidelines for the treatment of malaria (Brazilian Ministry of Health, 2010) [8]. Patients with uncomplicated $P$. vivax malaria received non-supervised chloroquine for three days (four pills on day 1 and three pills on both days 2 and 3) and nonsupervised primaquine (15 mg daily for 14 days). In cases of true relapse, the dose of primaquine was increased to $22.5 \mathrm{mg} /$ day for 14 days; if there was a second relapse, the dose was increased to $30.0 \mathrm{mg} /$ day for 14 days. Patients with uncomplicated $P$. falciparum malaria received a single oral mefloquine dose at admission (prior to 2007) or artesunate plus mefloquine p.o. for three days (20072011). Intramuscular artemether was given to 18 patients with severe disease. There was no information available on chemoprophylaxis.

\section{Statistical analyses}

Fisher's exact test was used for categorical data. Student's $t$-test was used to compare groups with normally distributed data, and data sets with non-normal distributions were compared using the Mann-Whitney test. 
GraphPad Prism $5^{\circ}$ and Stata $9^{\circ}$ software were used for these analysis.

\section{Results}

\section{General findings}

Amongst a list of 415 subjects obtained from the NVE in 2011, only 263 patients had charts, of which four charts could not be retrieved and 35 cases were not confirmed as malarial infections after microscopic diagnosis. Therefore, clinical and epidemiological data were only retrieved from 224 patients (Figure 1). Plasmodium vivax malaria accounted for the majority of the cases $(n=151$; 67\%), while $P$. falciparum was identified in 67 patients $(30 \%)$ and mixed infection $(P$. vivax $+P$. falciparum $)$ was found in only six patients. No cases of infection by other Plasmodium species were reported. The distribution of cases per species and year is shown in Figure 2. The majority of infected people were men $(\mathrm{n}=186 ; 83 \%)$ for both $P$. vivax and $P$. falciparum infections (Tables 1 and 2). Eleven patients (7\%) who were at least 30 years old had diabetes-a proportion very close to that of the Brazilian population of the same age group-and 17 patients (21\%) who were at least 45 years old had hypertension. Three patients (1\%) had AIDS, and one of these cases had progressed to severe disease due to $P$. vivax.

The possible place of infection could be retrieved in 205 cases. Of these, 168 infections (82\%) took place in Brazil and 37 cases were from other countries, those were called 'international' cases, representing $18 \%$ of the total. The leading foreign country regarding the number of cases was Angola (13 cases, 6.3\%), followed by Haiti and Guiana (3 cases each), French Guiana, Ghana, Congo and Mozambique (2 cases each), and Venezuela, Cape Verde, Guinea Bissau, Equatorial Guinea, Cameroon, Egypt, South Africa and Papua New Guinea (1 case each).

\section{Malaria clinical complications and severity}

Severe malaria was defined according to the WHO criteria $[9,10]$. Among 21 patients $(9 \%)$ who presented with severe malaria, there were 14 cases of $P$. vivax infections, seven cases of $P$. falciparum infections Therefore, $9 \%$ of the P. vivax infections and $10 \%$ of the P. falciparum infections evolved into severe disease; these proportions were not significantly different $(P>0.05)$. Notably, no patient with severe disease was a resident of the probable area of infection, as five months was the longest stay.

Six of the 224 patients (3\%) presented with spontaneous bleeding of the nose and/or gums. All of these patients had $P$. vivax malaria, but no significant difference for this sign between P. falciparum and P. vivax was found. Four of these six patients presented thrombocytopaenia (platelet count $<150,000 / \mathrm{mm}^{3}$ ), which is not a criterion for severe malaria according to WHO guidelines [9].

From the 41 patients with available urine test data, eight subjects had haemoglobinuria. These cases included six $P$. vivax infections ( $4 \%$ of the total $P$. vivax malaria cases) and two P. falciparum infections (3\% of the total $P$. falciparum malaria cases). Among the four patients who

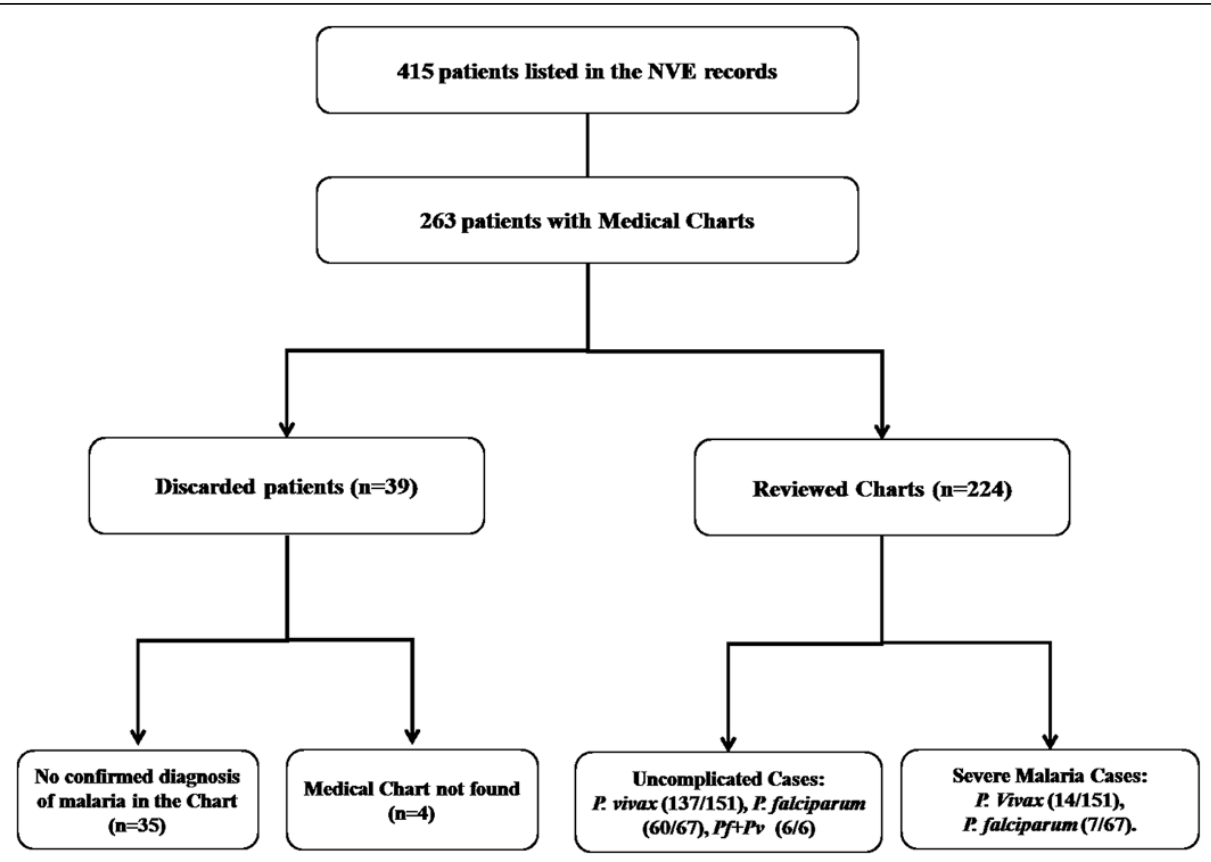

Figure 1 A flow diagram of medical chart selection. There were 415 names retrieved from the Center for Epidemiological Surveillance at UNICAMP. Of these, 263 were of patients with medical charts, but 35 of them had no confirmed diagnosis of malaria by TBF and 4 charts were not found, so only 224 charts were reviewed. 


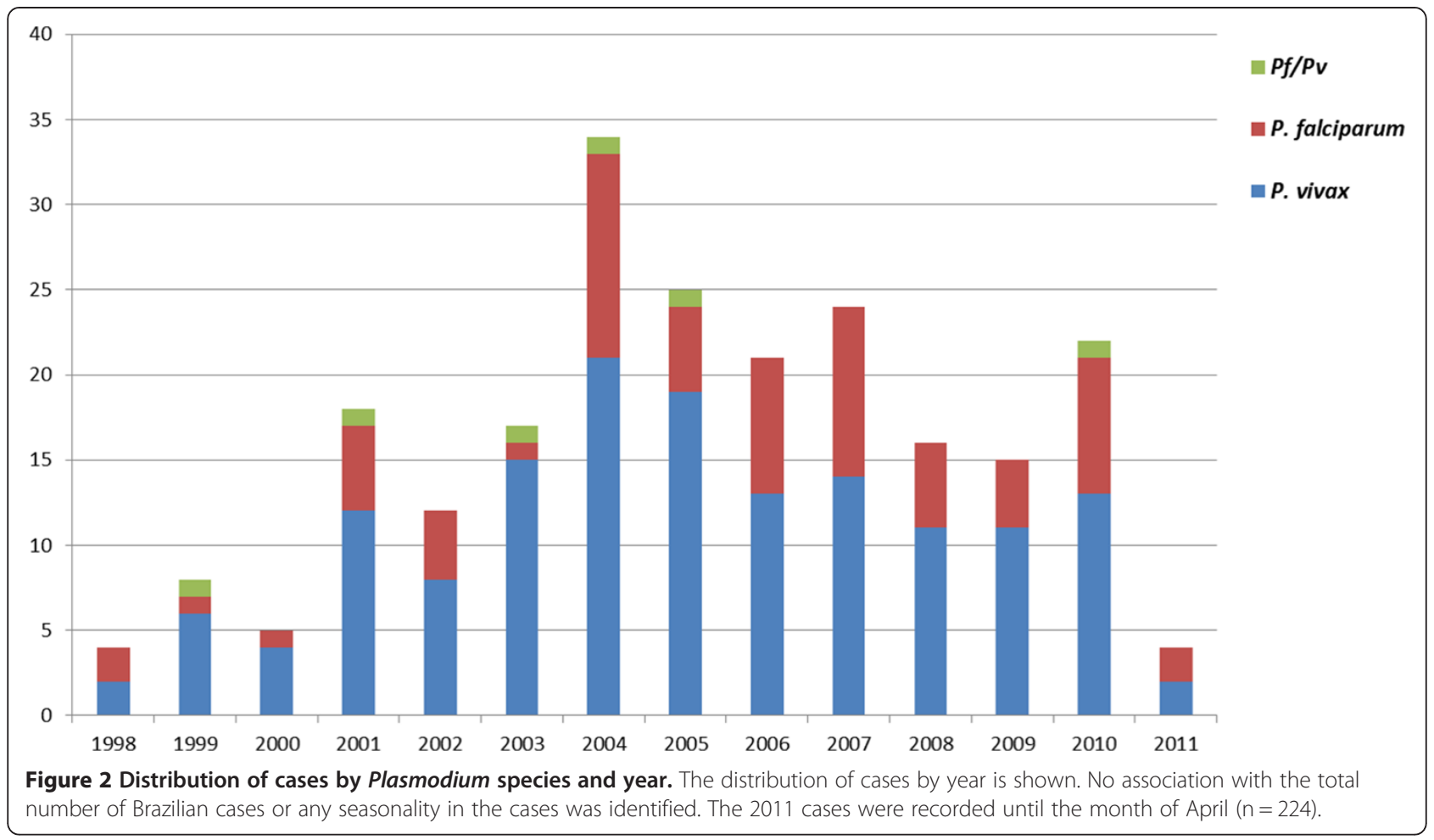

presented with type 1 respiratory failure $\left(\mathrm{pO}_{2}<60 \mathrm{mmHg}\right.$ and $\mathrm{pCO}_{2}<35 \mathrm{mmHg}$ ) [11], three had P. falciparum malaria and one had $P$. vivax malaria.

Hyperbilirubinaemia (total bilirubin $>3.0 \mathrm{mg} / \mathrm{dL}$ ) is considered to be a marker of severe disease only if it is associated with another indicator of organ dysfunction [12]. Following this criterion, five patients presenting with hyperbilirubinaemia and renal failure were considered to be patients with severe disease. For renal

Table 1 Demographic profile of malaria patients at HC-UNICAMP in the period 1998-2011

\begin{tabular}{|c|c|c|c|c|c|c|}
\hline \multirow{3}{*}{ Variable } & \multicolumn{6}{|c|}{ Infectious species } \\
\hline & \multicolumn{2}{|c|}{ P. falciparum } & \multicolumn{2}{|c|}{ P. vivax } & \multicolumn{2}{|c|}{$P f / P v$} \\
\hline & Freq. & (\%) & Freq & (\%) & Freq. & (\%) \\
\hline $\mathrm{N}$ & $68 / 224$ & (30) & $150 / 224$ & (67) & $6 / 224$ & (3) \\
\hline \multicolumn{7}{|l|}{ Gender: } \\
\hline Male & $59 / 67$ & $(88)^{a}$ & $124 / 151$ & (82) & $3 / 6$ & $(50)^{\mathrm{a}}$ \\
\hline Female & $8 / 68$ & (12) & $27 / 150$ & (18) & $3 / 6$ & $(50)$ \\
\hline \multicolumn{7}{|l|}{ Age: } \\
\hline Mean \pm SD & 35 & \pm 13 & 40 & \pm 16 & 26 & \pm 18 \\
\hline Median [p25-p75] & 35 & {$[26-45]^{a}$} & 39 & {$[28-52]^{a}$} & 19 & {$[15-41]$} \\
\hline \multicolumn{7}{|l|}{ Ethnicity: } \\
\hline White & $45 / 65$ & (69) & $117 / 148$ & (79) & $5 / 6$ & (83) \\
\hline Mixed & $12 / 65$ & (18) & $27 / 148$ & (18) & $1 / 6$ & (17) \\
\hline Black & $8 / 68$ & (12) & $4 / 148$ & (3) & $0 / 6$ & (0) \\
\hline
\end{tabular}

failure, it was considered a creatinine level $>1.5 \mathrm{mg} / \mathrm{dl}$ $[13,14]$. Of note, this value does not correspond to the WHO criterion for renal failure in severe malaria, and the patients were considered to have severe malaria for the concomitant presence of an altered serum creatinine and serum bilirubin. No patient met the WHO criteria for severe anemia, cerebral malaria, circulatory collapse, hypoglycaemia, acidosis or hyperlactataemia.

\section{Malaria relapses}

There were 19 (12.6\%) cases of true relapses amongst patients infected with $P$. vivax infections. For these relapsing episodes, the drug regimen was either maintained or the primaquine dose was increased. Among patients with relapses, four presented no symptoms during the relapse, four required hospitalization and 14 presented with fever. Thrombocytopaenia and anaemia were common findings, occurring in $69 \%$ and $60 \%$ of patients with relapses, respectively. Most of the relapses resolved after the first retreatment, but five patients (26\%) experienced more than one relapse.

\section{Laboratory admission findings}

Thrombocytopaenia (platelet count $<150,000 / \mathrm{mm}^{3}$ ) [15] was the most common finding in laboratory tests at the time of diagnosis, affecting 128 of 150 patients (85\%). This proportion did not vary significantly between the groups with severe or uncomplicated disease or between Plasmodium species. Twenty-eight patients had severe thrombocytopaenia (platelet count $<50,000 / \mathrm{mm}^{3}$ ) [16]. 
Table 2 Clinical profile of malaria patients at HC-UNICAMP in the period 1998-2011

\begin{tabular}{|c|c|c|c|c|c|}
\hline \multirow{2}{*}{ Variable } & \multicolumn{4}{|c|}{ Infectious species } & \multirow{2}{*}{$P$ value } \\
\hline & \multicolumn{2}{|c|}{ P. falciparum } & \multicolumn{2}{|c|}{ P. vivax } & \\
\hline Days of symptoms prior to diagnosis & $N=53$ & & $N=100$ & & \\
\hline Median [IQR] & 4 & {$[3-7]$} & 6 & {$[4-9]$} & 0,0326 \\
\hline Hospitalization (\%) & $35 / 67$ & (52) & $30 / 151$ & (20) & $<0,0001$ \\
\hline Days of hospitalization & $N=35$ & & $N=29$ & & \\
\hline Median [IQR] & 4 & {$[2-6]$} & 3 & {$[2-4]$} & 0,1701 \\
\hline Days since return from endemic area & $N=40$ & & $N=59$ & & \\
\hline Median [IQR] & 10 & {$[5-14]$} & 15 & {$[8-25]$} & 0,0078 \\
\hline Months in endemic area* & $N=29$ & & $N=57$ & & \\
\hline Median [IQR] & 1 & {$[0,6-4,5]$} & 1 & {$[0,5-2,5]$} & 0,2136 \\
\hline Referred fever (\%) & $61 / 67$ & (91) & $125 / 151$ & (83) & 0,1465 \\
\hline Referred shivers (\%) & $29 / 67$ & (43) & $73 / 151$ & (48) & 0,5569 \\
\hline Referred headache (\%) & $45 / 67$ & (67) & $80 / 151$ & (53) & 0,0550 \\
\hline Referred myalgia (\%) & $33 / 67$ & (49) & $69 / 151$ & (46) & 0,6607 \\
\hline Arthralgia (\%) & $10 / 11$ & (91) & $22 / 32$ & (69) & 0,2370 \\
\hline Vomiting (\%) & $25 / 36$ & (69) & $24 / 44$ & (55) & 0,2488 \\
\hline Sweating (\%) & $10 / 14$ & (71) & $17 / 28$ & (61) & 0,7337 \\
\hline Tachypnea (\%) & $9 / 18$ & (50) & $5 / 12$ & $(42)$ & 0,7220 \\
\hline Jaundice (\%) & $22 / 34$ & (65) & $19 / 46$ & (41) & 0,0448 \\
\hline Splenomegaly (\%) & $22 / 43$ & (51) & $20 / 58$ & (34) & 0,1060 \\
\hline
\end{tabular}

*Only patients considered to be travellers ( $<12$ months in endemic area).

Of those, 14 were patients with $P$. vivax malaria (15\%) and 14 were patients with $P$. falciparum malaria (27\%). The difference between these proportions was not significantly different (Table 3 ).

Overall, 52/152 patients (34\%) were found to be anaemic $(\mathrm{Hb}<11 \mathrm{mg} / \mathrm{dL}$ for females and $\mathrm{Hb}<13 \mathrm{mg} / \mathrm{dL}$ for males) [17]. When comparing patients with severe disease to those with non-severe disease, $57 \%(16 / 28)$ of patients in the severe group were anemic compared to $29 \%(36 / 124)$ of patients in the non-severe group. The white blood cell (WBC) count was not different amongst the different groups of patients and a small proportion of patients (17\%, 25 of 146 patients) were leukopenic.

Laboratory test results were only different between patients with $P$. falciparum or $P$. vivax malaria for prothrombin time (PT), lactate dehydrogenate (LDH) and aspartate aminotransferase (AST), were slightly elevated only for LDH and AST in P. falciparum infections (Table 4). As the sample sizes were small for LDH, a biomarker that was not part of routine evaluations of malaria cases, this difference might be biased. No further investigations were carried out to investigate the difference in AST levels.

As expected, a significant decrease in haemoglobin, haematocrit and red blood cell levels in the first days after the onset of treatment was detected $(P<0.0001)$. A significant reduction in WBC was also found, but both median values were within the reference range.

\section{Discussion}

The proportion among of Plasmodium species that caused infection in the present study cohort was different from what is observed in Brazil as a whole (where P. vivax accounts for nearly $85 \%$ of cases), but was very similar to what has been previously reported for this region [6,7]. A higher incidence of $P$. vivax infections, compared to $P$. falciparum infections, is different from what is observed in Europe and the USA, where most imported cases come from Africa [18-20], but is similar to what is observed in Australia, where most cases come from Asia [16,21]. Notably, although the peak of cases detected in our study in 2004 does not directly mirror the profile of Brazil, where the highest incidence of malaria cases took place in 2005; however, 2004 was still marked by one of the highest number of cases [22]. Otherwise, no special event was found that would fully explain this pattern.

The high frequency of 'international' cases derived from Angola (34\%) probably reflects the fact that both Brazil and Angola are former Portuguese colonies. The relationship of imported cases in European countries with their former African colonies is a well-known phenomenon [23]. 
Table 3 Laboratory admission values of malaria patients at HC-UNICAMP during 1998-2011

\begin{tabular}{|c|c|c|c|}
\hline \multirow{2}{*}{ Variable } & \multicolumn{2}{|c|}{ Infectious species } & \multirow{2}{*}{$\begin{array}{l}P \\
\text { value }\end{array}$} \\
\hline & P. falciparum & P. vivax & \\
\hline \multirow[t]{2}{*}{ Platelets $\left(150-450 \times 10^{3} / \mathrm{ml}\right)$} & $N=53$ & $N=93$ & \multirow{2}{*}{0,974} \\
\hline & $83[46,5-122]$ & $81[53-109,5]$ & \\
\hline \multirow[t]{2}{*}{ Haemoglobin (13-17 mg/dl) } & $N=55$ & $N=94$ & \multirow{2}{*}{0,507} \\
\hline & $13,2[12,2-14,5]$ & $13,7[12,6-14,6]$ & \\
\hline \multirow[t]{2}{*}{ Haematocrit (42-52\%) } & $N=41$ & $N=75$ & \multirow{2}{*}{0,806} \\
\hline & $40[37-42]$ & $40[36-43]$ & \\
\hline \multirow[t]{2}{*}{ Erythrocytes $\left(4.5-6.1 \times 10^{6} / \mathrm{ml}\right)$} & $N=35$ & $N=75$ & \multirow{2}{*}{0,687} \\
\hline & $4,43[4,06-4,76]$ & $4,51[4,11-5,01]$ & \\
\hline \multirow[t]{2}{*}{ Leukocytes $\left(4-10 \times 10^{3} / \mathrm{ml}\right)$} & $N=53$ & $N=91$ & \multirow{2}{*}{0,219} \\
\hline & $5,4[4,0-6,5]$ & $5,4[4,3-6,8]$ & \\
\hline \multirow[t]{2}{*}{ AST ( $\leq 37 \mathrm{U} / \mathrm{L})$} & $N=43$ & $N=61$ & \multirow{2}{*}{0,029} \\
\hline & $40[27-71]$ & $32[20,5-46]$ & \\
\hline \multirow[t]{2}{*}{$\operatorname{ALT}(\leq 40 \cup / L)$} & $N=42$ & $N=60$ & \multirow{2}{*}{0,088} \\
\hline & $42,5[24,8-97,2]$ & $31,5[19,5-61,8]$ & \\
\hline \multirow[t]{2}{*}{ GGT ( $\leq 40$ U/L) } & $N=21$ & $N=23$ & \multirow{2}{*}{0,204} \\
\hline & 61 [33-200] & $58[23-75]$ & \\
\hline \multirow[t]{2}{*}{ Total Bilirubin ( $\leq 1.0 \mathrm{mg} / \mathrm{dl})$} & $N=35$ & $N=48$ & \multirow{2}{*}{0,210} \\
\hline & $1,60[0,97-4,98]$ & $1,18[0,95-2,18]$ & \\
\hline \multirow[t]{2}{*}{ PT (INR) $(\leq 1.25)$} & $N=28$ & $N=36$ & \multirow{2}{*}{0,015} \\
\hline & $1,24[1,1,35]$ & $1,15[1,06-1,24]$ & \\
\hline \multirow[t]{2}{*}{$\mathrm{PTT}(\mathrm{R})(\leq 1.30)$} & $N=28$ & $N=36$ & \multirow{2}{*}{0,401} \\
\hline & $1,20[1,1,33]$ & $1,14[1,01-1,32]$ & \\
\hline \multirow[t]{2}{*}{ LDH (240-479 U/L) } & $N=11$ & $N=12$ & \multirow{2}{*}{0,013} \\
\hline & 751 [661-838] & 464 [397-552] & \\
\hline \multirow[t]{2}{*}{ Creatinine (0.7-1.3 mg/dl) } & $N=45$ & $N=64$ & \multirow{2}{*}{0,647} \\
\hline & $1,07[0,78-1,22]$ & $0,98[0,88-1,15]$ & \\
\hline
\end{tabular}

$\mathrm{N}$ refers to the absolute number of patients with the respective laboratory test information available.

Nonetheless, in contrast to cases included in European studies [24,25], the number of cases associated with visiting friends and relatives in endemic countries was very small in the group of 'international' cases. Business travellers and recent African immigrants made up the majority of patients infected in former Portuguese colonies in our study. The lack of patients who had been infected in African countries during travels to visit friends and relatives may indicate that the relationships between two former colonies or a former colony and colonizer differ.

The higher proportion of infected men, a common finding among imported malaria studies [26,27], resulted from the occurrence of most infections when patients travelled to endemic areas, especially for work-related reasons. This result could indicate that either men are employed in jobs associated with the greatest risk of infection or men still more often occupy the position of family provider [28]. This is exemplified by the observation that amongst 111 patients with registered occupations, 21 (19\%) were male truck drivers, an occupation at risk of infection during trips to endemic areas. Of some interest was the finding that all cases originating in Haiti (3 cases) affected Brazilian soldiers who were on humanitarian deployments for the UN and were also men of working age.

There was no significant difference in the time elapsed between the onset of symptoms and the initiation of treatment when cases of $P$. falciparum and $P$. vivax were compared. The finding that there was no greater time interval between the onset of symptoms and treatment for cases of complicated $P$. vivax or P. falciparum malaria is of critical importance, as it suggests that a longer disease duration and increased parasitaemia are not sufficient to yield complications of $P$. vivax malaria, and the development of severe disease might also depend on other factors intrinsic to the parasite species [29].

Of particular interest is the finding that no patients with severe malaria were residents of endemic areas, which supports the concept of greater vulnerability of non-immune patients, or those with waning immunity, to the development of severe presentations of the disease [1]. This information is of paramount importance, as it serves as a warning to health professionals and systems located far away from endemic areas to be alert for patients presenting with signs of malaria, especially $P$. vivax malaria, which is still perceived to be a

Table 4 Proportion of clinical signs among severe malaria cases met at HC-UNICAMP during 1998-2011

\begin{tabular}{|c|c|c|c|c|c|c|}
\hline \multirow{3}{*}{ Parameter } & \multicolumn{6}{|c|}{ Infecting species } \\
\hline & \multicolumn{2}{|c|}{ Overall } & \multicolumn{2}{|c|}{ P. falciparum } & \multicolumn{2}{|c|}{ P. vivax } \\
\hline & Freq & (\%) & Freq & (\%) & Freq & (\%) \\
\hline $\bar{N}$ & 21 & $(100)$ & 7 & $(100)$ & 14 & $(100)$ \\
\hline Bleeding & $6 / 21$ & $(29)$ & $0 / 7$ & $(0)$ & $6 / 14$ & $(43)$ \\
\hline Haemoglobinuria & $8 / 21$ & (38) & $2 / 7$ & (29) & $6 / 14$ & $(43)$ \\
\hline Hyperbilirrubinaemia + Renal Impairment & $6 / 21$ & $(29)$ & $3 / 7$ & (43) & $2 / 14$ & $(14)$ \\
\hline Respiratory Failure & $4 / 21$ & (19) & $3 / 7$ & (43) & $1 / 14$ & (7) \\
\hline
\end{tabular}

There was no difference in the frequency of clinical signs between the infecting species, as calculated with Fisher's Exact Test. 
benign disease $[4,30]$. One patient developed respiratory failure due to complicated $P$. vivax malaria, a finding previously reported in other Brazilian studies [31,32]. Six patients with $P$. vivax malaria presented with haemoglobinuria ( $4 \%$ of $P$. vivax cases), a rate of incidence similar to what has been observed previously in a multicenter study of endemic areas [33], but the proportions may vary [34] and previous studies on this topic focused on P. falciparum malaria.

Thrombocytopaenia was a common finding that affected $85 \%$ of patients analysed, a proportion comparable to other studies of imported malaria [16,35]. This finding reinforces the idea that thrombocytopenia in patients returning from areas endemic for malaria should alert a physician to the possibility of this disease. The prevalence of severe thrombocytopaenia (platelet count $<50,000 / \mathrm{mm}^{3}$ ) [16] was also relatively high, presenting in $12.5 \%$ of patients. The lack of data correlating platelet levels and bleeding does not prove the absence of an association, as some instances of minor bleeding may have not been registered in the medical charts. Anaemia was found in $34 \%$ of patients upon admission, a value close to what has been reported in a previous study on imported malaria in the Canary Islands [20], in which the majority of cases were caused by $P$. falciparum. From the beginning of treatment of patients with anti-malarials, there was a reduction in haemoglobin, haematocrit and red blood cells, as previously reported [36]. This pattern was observed both in patients with $P$. falciparum and $P$. vivax malaria, and anaemia worsened both in patients that received chloroquine and primaquine or mefloquine and artesunate.

Notably, from 2001 to 2011, there were 2391 cases of malaria in São Paulo, with 28 deaths caused by malaria in this state, a lethality rate of $1.1 \%[37,38]$. This lethality rate is more than 30 times greater than the rate in the Amazon area, according to official statistics [37]. Nevertheless, no deaths were observed at the HC-UNICAMP in this study. According to national statistics, there were three deaths in the region of Campinas during the study period, resulting in a lethality rate that was similar to that of the State of São Paulo. Although the lethality of the cases in Brazil that occurred outside of the Amazon Region in our study differs from previous studies [2,3], in which an 80 to 100 times higher lethality rate was reported, the findings in this study still support the notion that cases in non-endemic areas of Brazil are associated with an augmented risk of complications.

Analysing the incidence of relapsing cases along with associated factors is important for preventing such events. Relapses are dangerous because of their morbidity and risk of reintroducing malaria to areas where mosquito vectors are still present [39]. The occurrence of $12.6 \%$ P. vivax relapses that we found is lower that what was previously observed in other studies of imported malaria in Brazil [40,41], but the lack of monitoring for a cure after a first bout of treatment and distinct study methods might account for this difference. The adequacy of the primaquine dose for the weight of a patient in the HC-UNICAMP was only adopted after the study period and this may contribute to a lower incidence of relapses in the subsequent years. It is also relevant to highlight that as a reference center for malaria control in a non-endemic area, the University of Campinas Hospital is in a privileged location to study the mechanisms of malaria relapse and the development of primaquine resistance in the future.

There was no information about chemoprophylaxis for malaria in the medical charts. Thus, it was impossible to assess different disease severities or the presence of relapses based on this variable. The absence of such information might result from the recommendation by the Ministry of Health that chemoprophylaxis is only advised for persons travelling to areas with a high incidence of $P$. falciparum infection, which does not include most areas of Brazil, but it is important to highlight that prevention does not solely comprise chemoprophylaxis [42]. It is important to highlight that current travel advisory services in Campinas are restricted to the UNICAMP academic community and to medical consultancy in private companies.

\section{Study limitations}

Because this study took place in a tertiary hospital, there may have been some bias in the selection of patients, as subclinical or mild disease may have not compelled infected individuals seek out healthcare. Retrospective case series studies tend to face gaps in the register of information and the record of symptoms is somewhat biased because denied symptoms have a greater chance of not being registered in the medical chart than referred ones. Furthermore, it was not possible to exclude, from the medical charts, the presence of concomitant dengue fever in all of the cases, and this coinfection could explain cases of bleeding. Nevertheless, it was not possible to fully assess the presence of comorbities in all patients enrolled in the study.

The lack of a more sensitive method for malaria diagnosis in this study, especially PCR, makes it impossible to rule out the presence of mixed infection in the cases of severe vivax malaria. Nonetheless, TBF are systematically reviewed and a lower incidence of $P$. falciparum infection makes coinfection of Plasmodium species less likely.

\section{Conclusions}

This study has gathered much information about malaria in a region of Brazil outside of the Amazon, a subject 
that has received little attention by researchers. Despite the peculiarities of Brazilian culture, a concordance of the social aspects of imported malaria among the cases studied and of other studies of imported malaria in Latin America was observed. Based on the clinical and laboratory profiles of imported malaria cases in a non-endemic area of Brazil, infection with $P$. vivax was found to be responsible for severe cases. This finding reinforces the idea that $P$. vivax infections in Brazil are not benign and establishes a framework for further research on the topic. Indeed, more studies are needed on malaria in nonendemic areas in Brazil, especially with a prospective design and adequate exclusion of comorbidities and coinfection. Finally, considering the study area, the volume of cases treated and the possibility of secondary complications, the importance of referral malaria services that offer rapid and efficient diagnosis and treatment in Brazil is urgently apparent. There is also academic and scientific value in the study of malaria in non-endemic areas, because it is only in these areas that cases of relapses due to $P$. vivax can be studied without the interference of potential reinfections.

\section{Competing interests}

The authors declare that they have no competing interests.

\section{Authors' contributions}

JCKD collected the charts, performed and analyzed the data and wrote the first version of the manuscript. RNA, CMSC, SCPL, LA, MTA, CEL and MLM helped in data analysis and in the design of the study. MVGL and FTMC designed the study, helped in data analysis and wrote the final version of the manuscript.

\section{Acknowledgements}

Authors would like to acknowledge Maria da Conceição Chagas de Almeida, PhD, LEMB-CPQGM/FIOCRUZ, for the support with the handling and analysis of the data. Also the authors would like to acknowledge the Serviço de Arquivo Médico da UNICAMP and the NVE for the support with the access to the medical charts. The research was supported by the National Council of Scientific and Technological Development (CNPq, Brazil) and by the São Research Foundation (FAPESP, Brazil) grants.

\section{Author details}

'Departamento de Genética, Evolução e Bioagentes, Instituo de Biologia, Universidade Estadual de Campinas (UNICAMP), Campinas, SP, Brazil. ${ }^{2}$ Faculdade de Ciências Médicas, UNICAMP, Campinas, SP, Brazil. ${ }^{3}$ Seção de Epidemiologia Hospitalar, Hospital das Clínicas, UNICAMP, Campinas, SP, Brazil. ${ }^{4}$ Departamento de Clínica Médica, Faculdade de Ciências Médicas, UNICAMP, Campinas, SP, Brazil. ${ }^{5}$ Departamento de Patologia Clínica, UNICAMP, Campinas, SP, Brazil. ${ }^{6}$ Fundação de Medicina Tropical Dr. Heitor Vieira Dourado, Manaus, AM, Brazil. 'Universidade do Estado do Amazonas, Manaus, AM, Brazil.

Received: 6 April 2014 Accepted: 13 July 2014

Published: 22 July 2014

\section{References}

1. Nilles EJ, Arguin PM: Imported malaria: an update. Am J Emerg Med 2012, 30:972-980.

2. Brasil $P$, Costa AP, Longo CL, da Silva S, da Cruz MF F, Daniel-Ribeiro CT: Malaria, a difficult diagnosis in a febrile patient with sub-microscopic parasitaemia and polyclonal lymphocyte activation outside the endemic region, in Brazil. Malar J 2013, 12:402.
3. Costa AP, Bressan CS, Pedro RS, Valls-de-Souza R, Silva S, Souza PR, Guaraldo L, Ferreira-da-Cruz MF, Daniel-Ribeiro CT, Brasil P: Delayed diagnosis of malaria in a dengue endemic area in the Brazilian extra-Amazon: recent experience of a malaria surveillance unit in state of Rio de Janeiro. (in Portuguese). Rev Soc Bras Med Trop 2010, 43:571-574.

4. Costa FT, Lopes SC, Albrecht L, Ataíde R, Siqueira AM, Souza RM, Russell B, Reina L, Marinho CR, Lacerda MV: On the pathogenesis of Plasmodium vivax malaria: perspectives from the Brazilian field. Int J Parasito/ 2012, 42:1099-1105.

5. Barata R, Malaria in Brazil: Trends in the last ten years. Cadernos de Saúde Pública (FIOCRUZ) 1995, 11:128-136.

6. Alves M, Mayo R, Donalisio M: History, epidemiology and control of malaria in the region of Campinas, São Paulo State, Brazil, 1980-2000. (in Portuguese). Rev Soc Bras Med Trop 2004, 37:41-45.

7. Guideline: Hospital \& clinics, state university of Campinas. (in Portuguese). Available from: http://www.hc.unicamp.br/?q=node/178.

8. Practical guide for malaria treatment in Brazil. (in Portuguese): Practical Guide for Malaria Treatment in Brazil. (in Portuguese). In Ministério da Saúde. Edited by Brasilia. Brasília, Brazil: Brazilian Ministry of Health; 2010.

9. World Health Organization: Guidelines for the treatment of malaria. 2010.

10. Lacerda MV, Fragoso SC, Alecrim MG, Alexandre MA, Magalhães BM, Siqueira AM, Ferreira LC, Araújo JR, Mourão MP, Ferrer M, Castillo P, Martin-Jaular L, FernandezBecerra C, del Portillo H, Ordi J, Alonso PL, Bassat Q: Postmortem characterization of patients with clinical diagnosis of Plasmodium vivax malaria: to what extent does this parasite kill? Clin Infect Dis 2012, 55:e67-e74.

11. Santos LC, Abreu CF, Xerinda SM, Tavares M, Lucas R, Sarmento AC: Severe imported malaria in an intensive care unit: a review of 59 cases. Malar J 2012, 11:96.

12. Roussos C, Koutsoukou A: Respiratory failure. Eur Respir J Suppl 2003 $47: 3 s-14 s$.

13. Lacerda MV, Mourão MP, Alexandre MA, Siqueira AM, Magalhães BM, Martinez-Espinosa FE, Filho FS, Brasil P, Ventura AM, Tada MS, Couto VS, Silva AR, Silva RS, Alecrim MG: Understanding the clinical spectrum of complicated Plasmodium vivax malaria: a systematic review on the contributions of the Brazilian literature. Malar J 2012, 11:12.

14. O'Brien MM, Gonzales R, Shroyer AL, Grunwald GK, Daley J, Henderson WG, Khuri SF, Anderson RJ: Modest serum creatinine elevation affects adverse outcome after general surgery. Kidney Int 2002, 62:585-592.

15. Tavares MB, Chagas de Almeida Ma C, Martins RT, de Sousa AC, Martinelli R, dos-Santos WL: Acute tubular necrosis and renal failure in patients with glomerular disease. Ren Fail 2012, 34:1252-1257.

16. Stasi R: How to approach thrombocytopenia. Hematol Am Soc Hematol Educ Progr 2012, 2012:191-197.

17. Robinson P, Jenney AW, Tachado M, Yung A, Manitta J, Taylor K, Biggs BA: Imported malaria treated in Melbourne, Australia: epidemiology and clinical features in 246 patients. J Travel Med 2001, 8:76-81.

18. WHO: Haemoglobin Concentrations for the Diagnosis of Anaemia and Assessment of Severity. Geneva: World Health Organization; 2011.

19. Centers for Disease Control and Preventio: Malaria Surveillance — United States. 61st edition. Atlanta: MMWR 2012; 2010:2012.

20. Siikamäki H, Kivelä P, Lyytikäinen O, Kantele A: Imported malaria in Finland 2003-2011: prospective nationwide data with rechecked background information. Malar J 2013, 12:93.

21. Espinosa-Vega E, Martin-Sanchez AM, Elcuaz-Romano R, Hernandez-Febles M, Molina-Cabrillana J, Perez-Arellano JL: Malaria in paradise: characterization of imported cases in Gran Canaria Island (1993-2006). J Travel Med 2011, 18:165-172.

22. Charles DM, Hart J, Davis WA, Sullivan E, Dowse GK, Davis TM: Notifications of imported malaria in Western Australia, 1990-2001: incidence, associated factors and chemoprophylaxis. Med J Aust 2005, 182:164-167.

23. Oliveira-Ferreira J, Lacerda MV, Brasil P, Ladislau JL, Tauil PL, Daniel-Ribeiro CT: Malaria in Brazil: an overview. Malar J 2010, 9:115.

24. Millet JP, de Olalla PG, Gascon J, Prat JG, Trevino B, Pinazo MJ, Cabezos J, Munoz J, Zarzuela F, Cayla JA: Imported malaria among African immigrants: is there still a relationship between developed countries and their ex-colonies? Malar J 2009, 8:111.

25. Rey S, Zuza I, Martinez-Mondejar B, Rubio JM, Merino FJ: Imported malaria in an area in southern Madrid, 2005-2008. Malar J 2010, 9:290.

26. Smith AD, Bradley DJ, Smith V, Blaze M, Behrens RH, Chiodini PL, Whitty CJ: Imported malaria and high risk groups: observational study using UK surveillance data 1987-2006. BMJ 2008, 337:a120. 
27. Liu Y, Hsiang MS, Zhou H, Wang W, Cao Y, Gosling RD, Cao J, Gao Q: Malaria in overseas labourers returning to China: an analysis of imported malaria in Jiangsu Province, 2001-2011. Malar J 2014, 13:29.

28. Askling HH, Nilsson J, Tegnell A, Janzon R, Ekdahl K: Malaria risk in travelers. Emerg Infect Dis 2005, 11:436-441.

29. Rodriguez-Morales AJ, López-Zambrano MA, Harter-Griep R, Vilca-Yengle LM, Cárdenas R: Social aspcets of imported malaria in latin America. (in Spanish). Rev Peru Med Exp Salud Publ 2008, 25:208-216.

30. Carvalho BO, Lopes SC, Nogueira PA, Orlandi PP, Bargieri DY, Blanco YC, Mamoni R, Leite JA, Rodrigues MM, Soares IS, Oliveira TR, Wunderlich G, Lacerda MV, del Portillo HA, Araújo MO, Russell B, Suwaranusk R, Snounou G, Renia L, Costa FT: On the cytoadhesion of Plasmodium vivax-infected erythrocytes. J Infect Dis 2010, 202:638-647.

31. Price RN, Tjitra E, Guerra CA, Yeung S, White NJ, Anstey NM: Vivax malaria: neglected and not benign. Am J Trop Med Hyg 2007, 77:79-87.

32. Tan LK, Yacoub S, Scott S, Bhagani S, Jacobs M: Acute lung injury and other serious complications of Plasmodium vivax malaria. Lancet Infect Dis 2008, 8:449-454.

33. WHO: Clinical, Behavioural and Socioeconomic Factors Related to Severe Malaria. A Multicentre Study in the African Region. Brazzaville, Republic of Congo: WHO Regional Office for Africa; 2002.

34. Ajetunmobi WA, Orimadegun AE, Brown BJ, Afolabi NK, Olabiyi FA, Anetor $\mathrm{Jl}$, Omokhodion S, Osinusi K, Akinbami FO, Shokunb WA, Sodeinde O, Fernandez-Reyes D: Haemoglobinuria among children with severe malaria attending tertiary care in Ibadan. Nigeria Malar J 2012, 11:336.

35. Gjørup IE, Vestergaard LS, Møller K, Rønn AM, Bygbjerg IC: Laboratory indicators of the diagnosis and course of imported malaria. Scand I Infect Dis 2007, 39:707-713.

36. Douglas NM, Anstey NM, Buffet PA, Poespoprodjo JR, Yeo TW, White NJ, Price RN: The anaemia of Plasmodium vivax malaria. Malar J 2012, 11:135.

37. Mortality System Information. (in Portuguese). In. Edited by. Brasil: Ministério da Saúde. Available from: http://www2.datasus.gov.br/DATASUS/ index.php?area $=0205 \& \mathrm{VObj}=\mathrm{http}: / /$ tabnet.datasus.gov.br/cgi/deftohtm.exe? sim/cnv/obt10.

38. Information System for Notifiable Diseases. (in Portuguese). In. Edited by. Brasil: Ministério da Saúde. Available from: http://dtr2004.saude.gov.br/ sinanweb/index.php.

39. Limongi JE, Chaves KM, Paula MB, Costa FC, Silva Ade A, Lopes Ide S, Pajuaba Neto Ade A, Sales JM, Rodrigues F, Resende MA, Ferreira MS: Malaria outbreaks in a non-endemic area of Brazil, 2005. Rev Soc Bras Med Trop 2008, 41:232-237.

40. Boulos M, Amato V, Dutra A, Di Santi S, Shiroma M: Análise da freqüência de recaídas de malária por Plasmodium vivax em região não endêmica (São Paulo, Brasil). Rev Inst Med Trop S Paulo 1991, 33:143-146.

41. Pedro RS, Guaraldo L, Campos DP, Costa AP, Daniel-Ribeiro CT, Brasil P. Plasmodium vivax malaria relapses at a travel medicine centre in Rio de Janeiro, a non-endemic area in Brazil. Malar J 2012, 11:245.

42. Genton B, D'Acremont V: Malaria prevention in travelers. Infect Dis Clin North Am 2012, 26:637-654.

doi:10.1186/1475-2875-13-280

Cite this article as: Dos-Santos et al: Imported malaria in a non-endemic area: the experience of the university of Campinas hospital in the Brazilian Southeast. Malaria Journal 2014 13:280

\section{Submit your next manuscript to BioMed Central and take full advantage of:}

- Convenient online submission

- Thorough peer review

- No space constraints or color figure charges

- Immediate publication on acceptance

- Inclusion in PubMed, CAS, Scopus and Google Scholar

- Research which is freely available for redistribution

Submit your manuscript at www.biomedcentral.com/submit
C Biomed Central 